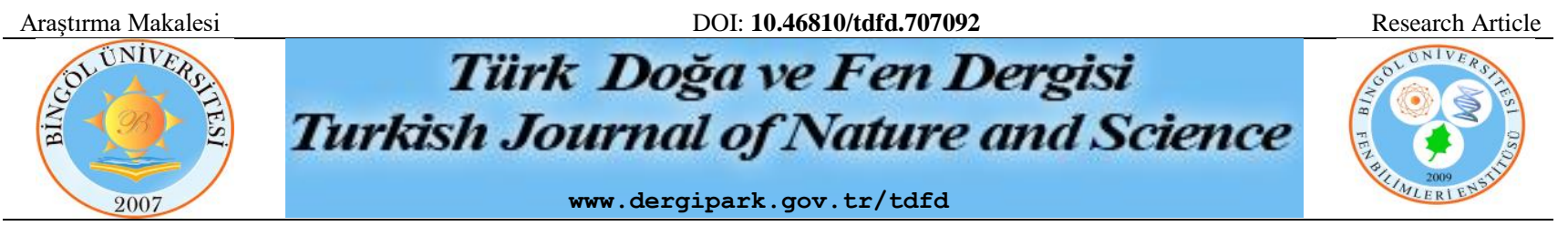

\title{
BREEAM Sertifikalı Bir Eğitim Binasının Yapım Maliyetinin Geleneksel Yapım Maliyetiyle Karşılaştırılması
}

\author{
Tahir AKGÜL ${ }^{1 *}$, İlknur BEȘKEN² ${ }^{2}$ Orhan KARABIYIKOĞLU ${ }^{3}$ \\ ${ }^{1}$ Sakarya Uygulamalı Bilimler Üniversitesi, Teknoloji Fakültesi, İnşaat Mühendisliği Bölümü, Sakarya / Türkiye \\ ${ }^{2,3}$ Sakarya Uygulamalı Bilimler Üniversitesi, L.E. Enstitüsü, İnşaat Mühendisliği ABD, Sakarya / Türkiye \\ Tahir AKGÜL ORCID No: 0000-0003-4826-9212 \\ İlknur BEŞKEN ORCID No: 0000-0002-0500-9018 \\ Orhan KARABIYIKOĞLU ORCID No: 0000-0001-5550-4677 \\ *Sorumlu yazar: tahirakgul@subu.edu.tr
}

(Alınış: 21.03.2020, Kabul: 27.05.2020, Online Yayınlanma: 18.06.2020)

\begin{abstract}
Anahtar
Kelimeler

Sürdürülebilir

yapilar,

Geleneksel

yapilar,

Eğitim yapıs1,

BREEAM,

Maliyet

Öz: Bu çalışmada; yeşil bina değerlendirme sistemleri içerisinde yer alan ve İngiltere menşeli olan Breeam Sertifika Değerlendirme Sistemine göre bir eğitim binasının minimum gereksinimler dikkate alınarak sürdürülebilir yeşil bina gereksinimleri projelendirilmiştir. Bu projede; sertifikasyon süreçlerinin, seçilen ekolojik malzemelerin, sürdürülebilirlik bağlamında kurulması kaçınılmaz olan sistemlerin, yapılan düzenlemeler ve seçimler sonucunda ortaya çıkan ek maliyetler belirlenmiştir. Öte yandan aynı statik projeye sahip geleneksel yapım tekniği ile yapılmış eğitim binasının yapım maliyeti ile karşılaştırılmıştır. Yapılan bu karşılaştırmalar sonucunda Breeam Sertifika Değerlendirme Sisteminde ön görülen minimum koşullarda ortaya çıkan ek maliyetin, geleneksel yapım sisteme göre yaklaşık \% 10 oranında arttığı sonucuna varılmıştır.
\end{abstract}

\section{Comparison of BREEAM Certified Construction Cost of a Training Building Compared to Traditional Construction Cost}

\begin{abstract}
Keywords Sustainable structures, Traditional structures, Educational structure, BREEAM, Cost
\end{abstract}

\section{GíRiş̧}

Gün geçtikçe gündelik hayatımızın her aşamasında sürdürülebilirlik kavramı ve sürdürülebilir yaşamın önemi artmakta bu nedenle yaşam alışkanlıklarımızı her alanda hızla değişmektedir. Günümüzde özellikle ekolojik dengenin bozulması ve küresel ısınma nedeniyle ortaya çıkan değişimlerden biri, yaşam alanlarımızın çevreye duyarlı, insan sağlığını önceleyen, sürdürülebilir olması gerekliliğidir. Yaşam alanlarımızın sürdürülebilir olması öncelikle yaşadığımız yapıların sürdürülebilir olmasına bağlıdır. Bundan dolayı birçok ülkede sürdürülebilir yapıların projelendirilmesi ve üretimi ile ilgili farklı sertifikasyon sistemleri geliştirilmiştir.

Dünyada enerji ihtiyaç düzeyi ve önemi her geçen gün artmaktadır. Yeşil bina sertifikasyon sistemleri, yapılarda enerji kullanımının daha verimli hale getirilerek gelecek kuşaklara daha yaşanabilir bir çevre bırakmak ilkesiyle hareket etmektedir. $\mathrm{Bu}$ nedenle günümüzde yaşam alanlarımızı yeşil bina değerlendirme sistemlerine uygun olarak inşa etmek bir ihtiyaçtan ziyade zorunluluk haline gelmiştir. $\mathrm{Bu}$ nedenle hem toplumun bu konuda bilinçlendirilmesi hem de yapılan yeşil binanın örnek teşkil ederek yaygınlaşmasını 
sağlamak son derece önemlidir. Böylece karbon salınımı düşük malzeme kullanımı, yenilenebilir enerji, bilinçli enerji tüketimi, yaşanabilir çevre, usulüne uygun geri dönüştürülen atıklar, insan sağlığını önceleyen yaşam alanı ile gelecek nesillere daha yaşanabilir bir dünya mirası bırakmak mümkün olacaktır [1].

Ayrıca sürdürülebilir yeşil binaların günlük hayata katkıları ve avantajları birçok akademik çalışmayla ortaya konulmuştur. Mesela Yeşil Okulun; Çevre, Sağlık ve Eğitim üzerine etkilerinin incelendiği bir çalışmada, yeşil okul tasarımının öğrenci başarısını olumlu yönde etkilediği görmüştür [2]. Yapılan bir başka çalışmada alışveriș merkezleri için yeşil bina performans ölçüm modeli önerisinde bulunulmuş sonuç olarak çevre kirliliği, iklim değişiklikleri, doğal kaynakların kullanımı gibi çevresel sorunların yanı sıra, insanlarda sürdürülebilir çevre bilincinin oluşmasına ve bu durumun yapı sektörünü de çevreyle dost, yeşil binalar inşa etmeye yönlendirdiği tespit edilmiştir [3].

Maliyet karşılaştırılması konusunda yapılan bir çalışmada Bursa ili Osmangazi ilçesi Çekirge semtinde toplam iç kullanım alanı $300 \mathrm{~m}^{2}$ olan klasik ofis ile yeşil ofis bina tasarımları ve maliyet hesapları yapılmıştır. Kendi enerjisini üreten yeşil ofis ile dışarıdan enerjisini alan klasik ofisin enerji sarfiyatları yıllık bazda belirlenmiş ve ilk yatırım maliyetlerine göre amortisman süreleri hesaplanmıştır. Yeşil ofisin maliyeti klasik ofisin maliyetleri karşılaştırılmış ayrıca kurulan sistemlerle yıllık tasarruf oranları ortaya çıkarılmıştır [4].

Yapılan bir başka çalışmada bir yapının enerji ihtiyacının karşılanması için yapıya kurulan sürdürülebilir enerji sistemleri olan rüzgar ve güneş enerjisi sistemlerinin verimleri karşılaştırılmıştır. Yapılan analizler sonucunda yapının enerji ihtiyacının güneş enerjisinden karşılaması uygun görülmüştür. $\mathrm{Bu}$ sistemle üretilen yıllık enerjinin sistem maliyetinin \%16 sını karşılamakta ve sistem maliyetinin 5,9 y1lda kendini amorti ettiği tespit edilmiştir [5].

Öte yandan ABD menşeli LEED ve İngiltere menşeli BREEAM sertifika programlarını karşılaştırılmasının yapıldığ 1 bir çalışmada; bu programların amaçları aynı olmasının yanı sıra hesaplama metotlarının farklı olduğu ortaya konulmuştur. Her iki sistemin de uygulamada bazı zorluklarla karşılaşıldığı ancak temel olarak sürdürülebilir yeşil bina sertifikası almanın sadece bir takım basit yöntemlerin izlenilmesiyle mümkün olacağına değinilmiştir [6].

Dünyada ilk olması bakımından büyük öneme sahip, İngiltere yeşil bina sertifika programı olan BREEAM (Building Research Establishment Environmental Assessment Method), binaların sürdürülebilirliğini değerlendiren, derecelendiren ve onaylayan bir sistemdir. Bu sistem sadece değerlendirme yapmayan, getirdiği öneriler ve grup çalışmaları ile inşaat tekniklerini değiştiren, yenilikçi fikirlere öncülük yapmaktadır. BREEAM sertifika programının temel amaçları; çevreye zarar vermeyen yapılar inşa etmek, kurumların çevre hedeflerine ulaşmalarını sağlamak, yenilikçi çözümler için teşvik etmek, yapıları çevresel uygulamalarla kontrol altına almak, kullanıcıların yeşil bina konusundaki bilinçlerini arttırmaktır [7].

BREEAM puanlama sisteminde puanlama, daha sürdürülebilir bir yapı inşa etmek, binanın marka değerini arttırmak ve en önemlisi binanın yapımı ve tüm kullanım ömrü boyunca çevreye verdiği zararı minimize etmek adına farklı bina tipleri için farklı inovatif yaklaşımlar, mühendislik pratiklerinin geliştirilmesini amaçlamaktadır [8].

\section{MALZEME VE YÖNTEM}

$\mathrm{Bu}$ çalışmada bir ilkokul binası projesi kullanılmıştır. Bu proje geleneksel yapım teknikleri dikkate alınarak ilgili yönetmenliklere göre tasarlanmıştır. Proje için Sakarya ili Serdivan ilçesinde imar durumu eğitim tesis alanı olarak belirlenmiş bir parsel seçilmiştir. Yapı Bodrum + 4 katlı olup yaklaşı $1800 \mathrm{~m}^{2}$ temel alanı üzerine kurulmuştur. Toplam inşaat alanı $9.115 \mathrm{~m}^{2}$ dir. Okulun $4000 \mathrm{~m}^{2}$ civarında bahçesi bulunmaktadır. Geleneksel yapım teknolojileri ile yapılacak bina maliyetleri Çevre ve Şehircilik Bakanlığının belirlediği müteahhit karı dahil KDV hariç birim fiyatlar kullanılmıştır.

Öte yandan ilgili eğitim binasının sürdürülebilir yeşil bina projelendirilmesinde BREEAM sertifikasyon sistemi esas alınmıştır. BREEAM sertifika sisteminde kullanılan kredi kategorileri şekil 1'de verilmiştir. Bu kategorilerin puanlama ağırlıkları; Yönetim \%12, Enerji $\% 19$, Sağlık ve konfor $\% 14$, Su \%6, Malzeme $\% 12$, Atık $\% 8$, Kirlilik \%6, Yenilikçilik \%10, Ekoloji \%10, Risk \%1 şeklinde belirlenmiştir [9].

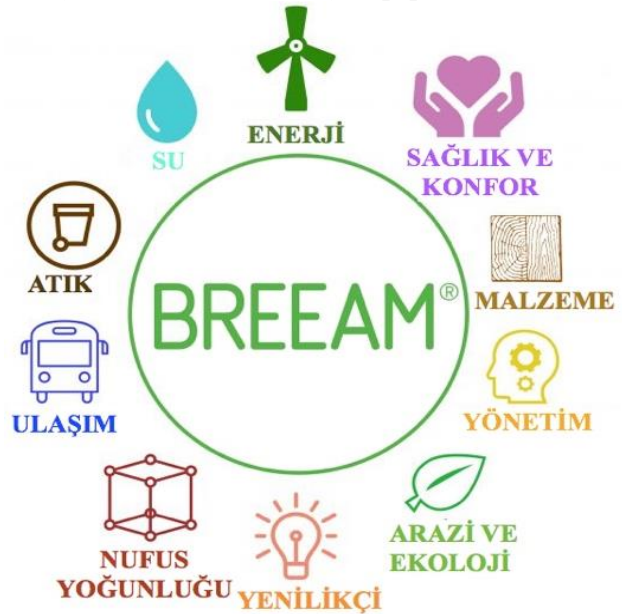

Şekil 1. BREEAM sertifika sisteminde dikkate alınan temel unsurlar [10]

Ayrıca ilgili sertifikasyon sisteminde minimum şartlar aranmaktadır. Buna göre;

1. Enerji; Breeam sertifikası içerisinde Enerji Verimliliği Değerlendirmesi konu başlığ $\breve{1}_{1}$ altında enerji puan hesaplama kartı bulunmaktadır. Bu puanın minimum 50 olmas1 gerekmektedir.

2. Havalandırma; Breeam'e göre tüm yaşanılabilir ve ıslak odaların asgari düzeyde havalandırma ve tahliye havalandırması bulunması gerekmektedir. Bu şartlar bina yönetmeliği kısım F, bölüm 7 de bulunmaktadır. 
3. Güvenlik; Breeam'e göre mutlaka yapı içerisinde yangın ve karbon monoksit algilama ve alarm sistemi olması gerekmektedir.

4. Malzeme; Breeam'de belirtilen CN3, CN8, CN9 ve CN11 inci kısımlara göre; Yapı içerisinde kullanılan tüm malzemelerin devlet lisanslı ve yasal olarak kullanmaya uygun olması gerekmektedir. Nesli tükenmekte olan malzeme türleri özellikle kereste türleri kullanılmamalıdır. Bu durum yapının konumuna ve ilgili yönetmeliğe göre değişkenlik gösterir. Kullanılan kaynağın sürdürülebilir olduğuna dair geçerliliği olan herhangi bir belge gerekir [9].

Yeşil bina sertifikasyonu için yapılacak çalışmalar, kurulacak sistemler ve düzeylerine göre puanlama sistemi yapılmaktadır. Tüm bu puanlamalar sonucunda yapının toplam puanına göre BREEAM sertifika seviyeleri belirlenmektedir. İlgili seviyeler şekil 2 de verilmiştir. Buna göre toplam skoru 30 puan altında kalan bir yapı Breeam'e göre yeşil bina statüsünde görülmemektedir. Öte yandan yapının puanı yükseldikçe yeşil bina düzeyi artmakta yani çevre, insan, enerji ve verimlilik vb. fayda düzeyi artmaktadır.

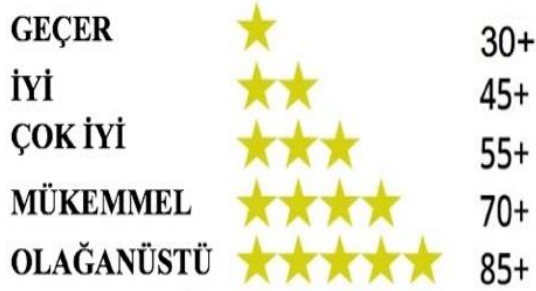

Şekil 2. BREEAM sertifika düzeyleri [10]

\section{BULGULAR VE TARTIŞMA}

Ele alınan proje yukarıda belirtilen kategorilere göre irdelenmiş ve her başlık altında yapılan faaliyetler ve maliyetleri ortaya konmuştur. Faaliyetler belirlenirken minimum sistem ve gereksinimlerle maksimum düzeyde fayda sağlamak ve yeşil bina için gerekli minimum skora ulaşmak amaçlanmıştır. Buna göre;

\subsection{Yönetim}

Yönetim bölümünün amacı, ev sahiplerinin evlerini verimli ve etkin bir şekilde işletebilmelerini ve güvenli bir evde yaşayabilmelerini sağlamaktır. Breeam Sertifikasına göre Yönetim kategorisi ev kullanım kılavuzu, ekolojik özelliklerin korunması ve geliştirilmesi, güvenlik ve proje yönetimi olmak üzere farklı başlıklar altında ele alınmıştır.

\subsubsection{Ev kullanım kılavuzu}

Bu kılavuz, binamızda güvenli, konforlu ve ekonomik işletilen bir ortam sunmak, bina tesliminden sonra karşılaşılması muhtemel soru ve sorunlara cevap vermek ve ev sahiplerine rehberlik sağlamak amacıyla hazırlanmaktadır. Breeam Sertifika programına göre Ev Kullanma Kılavuzu bölümündeki istenen koşullar sağlanmış olup buradan 3 kredi alınmıştır [11].

\subsubsection{Güvenlik}

İnsanların kendilerini güvende hissettiği yerel yenileme projelerini teşvik etmeyi; suç ve düzensizliğin olmadığ1, yaşam kalitesinin yüksek olduğu yerlerde yaşamalarını sağlamayı amaçlamaktadır. Okul binamızda kullanılan; Dış Kapı Takımları: PAS 24: 2007 ve LPS 1175 Issue 7 Security Rating, Pencereler: BS 7950: 1997 ve LPS 1175 Issue 7 Security Rating standartlarına uygunluk sağlamaktadır ve buradan 1 kredi kazanılmıştır. Ayrıca güvenlik görevlileri ve kameralar ile sağlanan güvenlik hizmeti ile 1 kredi elde edilmiştir.

\subsubsection{Ekolojik özelliklerin korunması ve geliștirilmesi}

Bölgenin, mevcut ekolojik özellikleri inşaat çalışmaları sırasında ve sonrasında önemli hasarlardan korumak ve ekolojik değerini arttırmayı amaçlamıştır. $\mathrm{Bu}$ amaçla bölgedeki ekolojik özelliklerin varlığını belirlemek için bir anket yapma taahhüdü verilmiştir. Ayrıca bölgede bulunan tüm ekolojik özelliklerin uygun şekilde korunacağının onayını alınmıştır ve böylelikle Ekolojik özelliklerin korunması ve geliștirilmesi bölümünden 1 kredi sağlamıştır.

\subsubsection{Proje yönetimi}

Amac1, performans beklentileri doğrultusunda tasarlanmış ve inşa edilmiş, işlevsel ve sürdürülebilir bir yenilemenin yapılmasını sağlamaktır. Proje ekibi arasında bireysel ve ortak sorumluluklar atamak için bir başlangıç toplantısı planlanmıştır. Buradan 1 kredi alınmıştır. Devir teslim sürecindeki ve sonraki bakım işlemleri sırasında havalandırma ve aydınlatma yeterliliği, enerji bilinci düzeyi, kullanım sonrası kusurların tespiti, sistemlerinin etkinliği ile ilgili sorunlar belirlenmesiyle 1 kredi de buradan elde edilmiştir.

\subsection{Sağlık ve Refah}

Sağlık ve Refah kategorisi, yaşayanlar için sağlıklı ve güvenli bir iç ortamı teşvik eden yenilemeleri tanıyarak yapılardaki yaşam kalitesini iyileştirmek amacıyla yapılan çalışmaları içermektedir. Bu kategoride üç ana başlıkta yapılan iyileştirme çalışmaları incelenecektir.

\subsubsection{Uçucu organik bileşikler}

Sağlık ve refah kategorisinin bu kısmında, uçucu organik bileșiklerin (VOC) düşük emisyonlu iç cilaların ve bağlantıların belirlenmesi yoluyla sağlıklı bir iç ortamın tanınması ve teşvik edilmesi amacıyla kullanılan tüm dekoratif boya ve verniklerin Breeam sertifika programına göre düzenlenmesi sağlanmıştır. Yapıda kullanılan standart tavan boyasi ve yine standart silikonlu iç cephe boyası yerine Breeam sertifika programının istediği özelliklere sahip bir tavan ve iç cephe boyası tercih edilmiştir. Seçilen tavan ve iç cephe boyası bünyesinde hiçbir zararlı kimyasal içermeyen, ortamın hava kalitesini iyileştiren Mas Cartified Green sertifikalı boyalardır. Kullanılan bu yeni boyalar sağlıklı ve güvenli bir iç ortam sağlayarak yaşam kalitesini iyileştirmeye katkı sağladığı için yapılan bu çalışmadan Breeam sertifika programına göre 1 kredi alınmıştır. 


\subsubsection{Havalandırma}

Temiz hava sağlamak için uygun havalandırma seviyelerinin sağlanması yoluyla sağlıklı bir iç ortamın tanınması ve teşvik edilmesi ve aşırı 1sı kaybı olmadan kirleticilerin ve nem seviyelerinin birikmesi ile ilgili sorunlardan kaçınmak amacıyla yapılması gereken çalışmaları içeren bu bölümde ek bir çalışma yapılmasına gerek duyulmamıştır. Bu konuda yapı inşası sirasında; hava kalitesi standartları konusunda Türkiye'de 2872 sayılı, 9 Ağustos 1983 kabul tarihli Çevre Kanunu'na dayanılarak 02.11.1986 tarihinde Hava Kalitesinin Korunması Yönetmeliği (HKKY) [12] gereğince gerekli şartların sağlanacağı kabul edilmiştir. Ayrıca Avrupa Birliği uyum sürecinde yapılan çalışmalar neticesinde Çevre ve Orman Bakanlığ 1 Hava Kalitesinin Korunması amacı ile bu yönetmeliği 3 farklı yönetmelik olarak düzenlemiş ve yürürlüğe koymuştur [13]. Bu yönetmeliklere uyulması yeterli olacak ve bu sayede 1 kredi alınacaktır.

\subsubsection{Güvenlik}

$\mathrm{Bu}$ bölümde yangın ve karbon monoksit (CO) maruziyetinden kaynaklanan yaşam, sağlık ve mal risklerini azaltmak amaçlanmaktadır. Binaların Yangından Korunması Hakkındaki Yönetmelik [14] kapsamında eğitim binaları inşası sırasında gerek duman detektörleri ve yağmurlama sistemi, gerek yangın merdiven ve holleri gerekli şekillerde ve şartnamelere uygun olarak projelendirilmiştir. $\mathrm{Bu}$ kısımdan hali hazırda projelendirme aşamasında 1 kredi alınmıştır.

\subsection{Enerji}

Enerji kategorisi, Breeam sertifika programına göre evin enerji verimliliğini artıracak önlemleri değerlendirmektedir. $\mathrm{Bu}$ kategoride yapılan iyileştirmeler beş alt başlikta incelenmiştir.

\subsubsection{Enerji verimliliği değerlendirme sonrası yenileme}

$\mathrm{Bu}$ değerlendirme kriterindeki amaç; $\mathrm{CO}$ salınımını azaltarak, yenilenmiş konutların Enerji Verimliliğini yüksek düzeyde teşvik etmektir. Ülkemizde enerji verimliliği konusunda yetkili belgeler Enerji Kimlik Belgeleridir. Hazırlatılan bu EKB belgesi ile yap1 içerisinde bulunan insanların bilinçlendirilmesi, var olan enerji ve emisyon sinıfları hakkında bilgi sahibi olunması sağlandıktan sonra ileriki adımlarda yapının CO salınım oranını azaltarak enerji ve emisyon sınıfları hakkında geliştirme yapılmasına imkan tanımaktır. Yapının enerji verimliliğinin değerlendirilmesi ve ileriye dönük yeni adımların planlanması sonucu bu bölümden 2 kredi alınmıştır.

\subsubsection{Enerji etiketli beyaz eşya}

Enerji tasarruflu beyaz eşya tedariki veya satın alınmasını teşvik etmek, böylece konuttaki cihaz kullanımından kaynaklanan karbondioksit $\left(\mathrm{CO}_{2}\right)$ emisyonlarını azaltmak amaçlanarak bu bölüm için gerekli inceleme ve araştırmalar yapılmıştır. İnşa edilecek yapımız bir okul binası olduğu için yapı içerisinde klimalar hariç kullanılacak bir beyaz eşya mevcut değildir. Bu yüzden yapıda kullanılan klimalar enerji etiketli $\mathrm{A}+++$ olarak seçilmiş bu sayede enerji verimliliğinden tasarruf ve $\mathrm{CO}_{2}$ emisyonunda da bir iyileştirme amaçlanmıştır. Yapılan çalışmalar sonucu enerji etiketli beyaz eşya bölümünden 2 kredi alınmıştır.

\subsubsection{Aydınlatma}

Okullarda elektrik tüketiminin yaklaşık \%30’u aydınlatmalardan kaynaklıdır. İyi bir aydınlatma hem tasarruf sağlar hem de gerekli 1şık konforunu sağlar. Bu konforun sağlanması için günümüzde az enerji tüketen ve floresan lambalara göre aynı performansı düșük enerji ile sağlayan LED spot lamba kullanmak doğru bir seçim olacaktır. Floresan ile LED spot lambamızı maliyet açısından karşılaştırdığımızda da \%100 tasarrufumuz söz konusudur. Bu uygulama ile Breeam Enerji bölümündeki aydınlatma ile istenen koşullar sağlanmış olup enerji kullanımı ve maliyeti düşürülmüştür. $\mathrm{Bu}$ bölümden sertifikaya göre 2 puan elde edilmiştir.

\subsubsection{Enerji teşhir cihazları}

Erişilebilir ekipmanın konut sakinlerine enerji tüketim verilerini göstermesini sağlamak ve böylece enerji kullanımını azaltmaya teşvik etmek amacıyla mevcut okul binasının her katına elektrik, su ve isınma verilerini toplayarak raporlamaya yarayan bir sistem yerleştirilecektir. Zenon Analyzer ile kaydedilen bu verilerden istenildiği gibi özel raporlar oluşturulabilmekte, bu raporlar istenilen dosya formatlarında kayıt edebilmektedir [15]. Seçilen bu sistemde, kayıt edilen veriler ve/veya online veriler ile dinamik raporlama yapabilmekte ve ISO50001 uyumlu standart raporları otomatik olarak hazırlayabilmektedir. $\mathrm{Bu}$ özelliği TUV tarafından test edilerek sertifikalandırılmıştır. Kullanılacak olan bu sistem ile enerji tüketim bedellerini kontrol edebilmesi sağlanacak ve 2 kredi alınacaktır.

\subsubsection{Döngü depolama}

Yeterli ve güvenli bisiklet depolama olanakları sağlayarak yolcuları bisiklet kullanmaya teşvik etmek, böylece kısa araba yolculuğu ihtiyacını azaltmak amacıyla okul bahçesi içerisine bisiklet sürücülerinin, bisikletlerini güvenli olarak birakabilecekleri, aydınlatması olan, motorlu taşıt trafiğinden arındırılmış ve bisikletlerin toplu olarak park edilebileceği istasyonlar ile bisiklet park yerleri ihtiyacı karşılayacak oranda yapılmıştır. Tasarım sırasında yönetmeliklere uyularak her 40 öğrenci için 8 park yeri standardına uyulmuş ve mevcut 620 öğrenci için 125 bisiklet park alanı oluşturularak bu bölümden 2 kredi alınmıştır [16].

\section{4. $\quad \mathrm{Su}$}

Bu çalışmadaki eğitim yapısının 'Breeam Sertifikası", alabilmesi için su kullanımı ile ilgili; Su kullanımını ölçmek ve kullanımı azaltmak amaçlanmış ve bunun için hem teknolojik gelişmeler kullanılmış hem de suyun geri dönüşümlü kullanılması sağlanmıştır. Çalışmadaki kişi sayısı 620 kişi olarak belirlenmiş olup ülkemizde ki günlük kişi başı su tüketimi MMO (sıhhi tesisat tekniğinde su tüketimi hesabı) verilerine göre okullarda 180 litre olarak belirlenmiştir. Breeam sertifikasında kullanılması zorunlu olan sensörlü musluk, kademeli sifon sistemi, çim sulama sistemi ve yağmur suyu toplama sistemi kullanılmış olup bu ürünlerin teknik 
şartnameleri dikkate alındığında, su sarfiyatları yukarıda bildirilen günlük kişi başı tüketimini azaltılmış olup tablo 1'de değerler verilmiştir. Çalışmada belirlenen şartlara uygun, tasarruf sağlayan yeni teknolojik malzemeler kullanılmış olup kişi başı günlük toplam su tüketimi 180 litre' den 75 litreye düşürülmüştür. Elde edilen bu tasarruf oranı Breeam Sertifikasından ekstra olarak 3 kredi kazandırmıştır. Ayrıca projede yağmur suyu depolama sistemi kurulmuş olup saniye' de 54,76 litre su depolama kapasitesine sahiptir. Elde edilen bu su daha sonra projede ki tuvalet bölümleri ve bahçe sulama sisteminde kullanılacak olup, ayrıca bir tasarruf sağlamış ve su kaynakları kullanımını azaltmıştır [17].

Tablo 1: Kişi Başı Günlük Toplam Su Tüketimleri [18]

\begin{tabular}{|l|c|c|}
\hline & $\begin{array}{c}\text { Kiși Bașı Günlük Toplam } \\
\text { Su Tüketimi (Litre) }\end{array}$ & $\begin{array}{c}\text { Kurulan sistemler Sonrası Kiși Bașı } \\
\text { Günlük Toplam Su Tüketimi (Litre) }\end{array}$ \\
\hline Musluk & 120 & 30 \\
\hline Rezervuar & 52 & 40 \\
\hline Çim Sulama Sistemi & 8 & 5 \\
\hline Toplam & 180 & 75 \\
\hline
\end{tabular}

\subsection{Malzeme}

Yapı içerisinde kullanılan tüm malzemelerin devlet lisanslı ve yasal olarak kullanmaya uygun olması gerekmektedir. $\mathrm{Bu}$ inşaatta kullanılan tüm malzemeler belirli standartlara sahiptir. Yeşil binalarda yaşam döngüsü analizinin yapılmış malzemeler tercih edilmektedir [19]. Yasal olmayan ve inşaata uygun olmayan hiçbir malzeme yapıda kullanılmamıştır. Projede diş duvarlarda 13,5'lik tuğla+EPS+3,5'lik tuğla kullanılmış yalıtım bu şekilde sağlanmıştır. Breeam Sertifikasına göre kullanılan malzemeler sonucunda bu kategoriden 4 kredi elde edilmiştir.

\subsection{Atık}

Atık kategorisi, tadilat çalışmalarından ve yapının işletilmesinden kaynaklanan atıkları azaltmayı, atıkların depolama alanından yönlendirilmesinin teşvik edilmesini amaçlayan konuları kapsamaktadır. Geri dönüştürülebilir atıklar için özel depolama alanlarının sağlanması ve teşvik edilmesi amacıyla çalışmalar yapılmış olup okul binasında ve bahçesinde geri dönüştürülebilir olan kağıt, cam, plastik, metal, pil atıkları için ayrı ve yeterli depolama ve toplama alanları oluşturulmuş, bu atıkların toplanmasına yönelik bir plan hazırlanmıştır. Yapılan çalışmalar sonucunda atık kategorisinden 2 kredi alınmıştır.

Sonuç olarak Breeam sertifikası geçer not alabilmek için yapılan çalışmaların 2019 yılı piyasa fiyat araştırması sonucu ortaya çıkan maliyet tablosu (tablo 2) ve kazanılan bölümlere ait puan tablosu (tablo 3) aşağıdaki tablolarda verilmiştir.
Tablo 2. Sertifikasyon çalışması kapsamında 2019 yılı piyasa araştırması sonucu ortaya çıkan maliyetler

\begin{tabular}{|c|c|}
\hline YAPILAN ÇALIȘMA & MALIYET \\
\hline Breeam Değerlendirme ve Danıșmanlık & $144.000,00$ も \\
\hline Güvenlik & $60.000,00$ も \\
\hline Peyzaj & $80.984,00$ も \\
\hline Tavan ve Cephe Boyası & $82.200,00$ も \\
\hline EKB Belgesi & $12.000,00$ も \\
\hline Klima ve Havalandırma Maliyeti Sis. & $161.184,00$ も \\
\hline Bisiklet Park Alanları & $11.250,00 も$ \\
\hline Enerji Teșhir Cihazları & $28.340,00$ も \\
\hline Musluk & $70.595,00$ も \\
\hline Klozet ve rezervuarlar & $32.926,00$ も \\
\hline Çim Sulama Sistemi & $8.252,00$ も \\
\hline Yağmur Suyu Depolama & $116.000,00$ も \\
\hline TOPLAM & $807.731,00$ も \\
\hline
\end{tabular}

Tablo 3. Sertifikasyon çalışmaları sonucunda ortaya çıkan puan tablosu

\begin{tabular}{|l|l|l|l|l|l|}
\hline $\begin{array}{c}\text { Breeam } \\
\text { Kategorileri }\end{array}$ & $\begin{array}{c}\text { Elde Edilen } \\
\text { Krediler }\end{array}$ & $\begin{array}{c}\text { Kullanulabilir } \\
\text { Kredi }\end{array}$ & $\begin{array}{c}\text { Elde Edilen } \\
\text { Kredilerin } \\
\text { Yüzdesi }\end{array}$ & $\begin{array}{c}\text { Bölüm } \\
\text { Ağırlığı }\end{array}$ & $\begin{array}{c}\text { Bölüm } \\
\text { Puanı }\end{array}$ \\
\hline Yönetim & 8 & 11 & 72,7 & 0,12 & 8,727 \\
\hline Sağlık Ve Refah & 5 & 12 & 41,7 & 0,17 & 7,083 \\
\hline Enerji & 10 & 29 & 34,5 & 0,43 & 14,828 \\
\hline Su & 3 & 5 & 60,0 & 0,11 & 6,600 \\
\hline Malzeme & 4 & 45 & 8,9 & 0,08 & 0,711 \\
\hline Atık & 2 & 5 & 40,0 & 0,03 & 1,200 \\
\hline Yenilik & & & & & 1,000 \\
\hline & Breeam Sertifika Puanı & & 40,15 \\
\hline
\end{tabular}

\subsection{Geleneksel Yapı Maliyetinin Belirlenmesi}

Yapılan çalışmada kullanılan okul projesinin geleneksel yapım maliyetinin hesaplanmasında Çevre ve şehircilik bakanlığının yayınladığı Mimarlık ve Mühendislik hizmet bedellerinin hesabında Kullanılacak 2019 yılı yap1 yaklaşık birim Maliyetleri tebliğinde B grubu yapılar temel eğitim yapıları $\mathrm{m}^{2}$ rayiç bedeli esas alınmıştır. Buna göre temel eğitim yapıları inşaat birim fiyatı $1210 \mathrm{tl} / \mathrm{m}^{2}$ dir. Ele alınan okul projesinin inşaat alanı yaklaşık olarak $9200 \mathrm{~m}^{2}$ olduğundan okulumuzun toplam yapım maliyeti 11 milyon Türk lirası olarak tespit edilmiştir [20].

\section{SONUÇLAR}

Çalışmada ele alınan okul binasının sürdürülebilir yapı sertifikasına sahip olması amaçlanmış ve öncelikle minimum (zorunlu) şartlar düşünülerek en az maliyetle maksimim fayda sağlayacak ve sertifikasyon programına göre geçer not almak için gerekli görülen uygulamalar belirlenmiş ve bu uygulamaların maliyetleri ortaya çıkarılmıştır. $\mathrm{Bu}$ çalışmalar sonucunda Breeam sertifikasından toplamda 40,15 puan elde edilmiştir. Bu skor Breeam'e göre geçer not olan 30 puanın üstünde olduğu için yeterli görülmektedir.

Ayrıca ortaya çıkan mali tablo incelendiğinde bu skora ulaşmak için gerekli olan sistem ve uygulamaların toplam maliyeti yaklaşık 800 bin tl dir.

Breeam'e göre geçer puan almak için tasarlanan faaliyet ve sistem maliyetleri yapının toplam maliyetinin yaklaşık \% 8'i kadar bir ek maliyet gerektirmektedir. Günümüz ve ülkemiz şartlarında Proje aşamasında 
belirlenen maliyetler ile gerçekleşen maliyet farkları dikkate alındığında beklenmeyen giderlerle bu oran maksimum \% 10 olacağı sonucuna ulaşılmıştır.

Öte yandan enerji ve su kategorilerinde yapılan düzenlemelerle günlük elektrik ve su tüketiminde gözle görülür düzeyde ve parasal değeri hesaplanabilen kaynak tasarrufu sağlanmıştır. Ayrıca atık malzemelerin geri dönüşümü, hava kalitesinin yükseltilmesi, sağlıklı ve güvenli bir ortamın sağlanması, sağlığa zararsız malzeme kullanımı, gri su tesisatıyla atık ve yağmur sularının değerlendirilmesi, ekolojik düzenlemelerle çevre tahribatının azaltılması, bisiklet kullanımı teşviki ile $\mathrm{CO}_{2}$ salınımında azaltılması yapılan çalışmalar sonucu ortaya çıkan parasal değeri hesaplanamaz faydalar elde edildiği görülmektedir.

Sonuç olarak sürdürülebilir yeșil binaların yukarıda sayılan faydaları ile ortaya çıkan ek maliyet kıyaslandığında yeşil binaların insan hayatına sağladığı konfor, sağlıklı yaşam alanı ve yaşanabilir çevre açısından kabul edilebilir bir düzeyde olduğu anlaşılmaktadır. Yapılan çalışma sonuçları itibariyle, gerek Breeam sertifikası gerekse sürdürülebilir yeşil binalar hakkında literatürde ifade edilen sonuçlarla paralel olduğu görülmektedir.

\section{KAYNAKLAR}

[1] Çelik, E. Yeşil Bina Sertifika Sistemlerinin İncelenmesi Türkiye'de Uygulanabilirliklerinin Değerlendirilmesi, Yüksek Lisans Tezi, İstanbul Teknik Üniversitesi, İstanbul; 2009.

[2] Demir, A. Yeşil Okul: Çevre, Sağlık Ve Eğitime Etkileri, Yüksek lisans tezi, İnönü Üniversitesi, Malatya; 2012.

[3] Nebati E. E. Ekmekçi İ. Alışveriş Merkezleri İçin Yeşil Bina Performans Ölçüm Model Önerisi. Gazi Mühendislik Bilimleri Dergisi. 2018; 4(3): 241255.

[4] Kılıç M.Y. Yahşi S. Sürdürülebilir Enerji Kullanımının Yeşil Bir Ofise Uygulanması. Gümüşhane Üniversitesi Fen Bilimleri Enstitüsü Dergisi. 2019; 9(3): 557-568.

[5] Güven, A.F. Bahçelievler Belediye Başkanlık Binasının Enerji İhtiyacının Güneş ve Rüzgar Sistemi ile Karşılanması, Optimizasyonu ve Maliyet Analizi. Sinop Uni J Nat Sci 2017; 2(1): 24-36.

[6] Somalı B. Ilıcalı E. Leed Ve Breeam Uluslararası Yeşil Bina Değerlendirme Sistemlerinin Değerlendirilmesi. IX. Ulusal Tesisat Mühendisliği Kongresi, İzmir; Mayıs 2009. p. 1081-1088.

[7] Erdede S. B. Erdede B. Bektaş S. Sürdürülebilir Yeşil Binalar ve Sertifika Sistemlerinin Değerlendirilmesi. V. Uzaktan Algılama ve Coğrafi Bilgi Sistemleri Sempozyumu UZAL-CBS 2014: İstanbul; Ekim 2014. p. 521-36.

[8] Jeffrey D. S. The Age of Sustainable Development. Columbia University Press. USA; 2015.

[9] http://www.breeam.org, (02.01.2020).

[10] https://www.erketasarim.com, (20.02.2020)
[11] ERTEN D. Yeşil Binalar. Sürdürülebilir Üretim ve Tüketim Yayınları V, Rec Türkiye: Ankara; 2017.

[12] Hava Kalitesinin Korunması Yönetmeliği. 19269 sayılı, 2 Kasım 1986 tarihli Resmî Gazete.

[13] Yemşen B. İç Ortam Hava Kalitesinin İyileştirilmesinde Mekanik Havalandırma Sistemlerinin Etkisi Ve Endüstriyel Bir Uygulama, Yüksek Lisans Tezi, Ege Üniversitesi, İzmir; 2016.

[14] Yangından Korunması Hakkındaki Yönetmelik. 12937 sayılı, 19 Aralık 2007 tarihli Resmî Gazete.

[15] Anonim. Yeni Nesil Otomasyon Yazılımı. Otomasyon Dergisi, 2018; 313(1): 92-94.

[16] Şehir İçi Bisiklet Yolları Kılavuzu. Çevre ve Şehircilik Bakanlığı. Ankara; Ağustos 2017.

[17] Alaş A. Tunç T. Kışoğlu M. Gürbüzan H. Öğretmen Adaylarının Bilinçli Su Tüketimi Davranışları Üzerine Bir Araştırma: Atatürk Üniversitesi Örneği. Erzincan Üniversitesi Eğitim Fakültesi Dergisi. 2009;11(2): 37-49,

[18] KÖKTÜRK U. Sıhhi Tesisat Tekniğinde Su Tüketimi Hesabı. TMMOB Makine Mühendisleri Odası. Tesisat Mühendisliği 21, 2010

[19] Akıncitürk M. Sürdürülebilirlik Ve Ekoloji Açısından Sertifikalı Konutların Analizi: İstanbul Örneği, Yüksek Lisans Tezi, İstanbul Kültür Üniversitesi, İstanbul; 2015.

[20] Mimarlık Ve Mühendislik Hizmet Bedellerinin Hesabında Kullanılacak 2019 Yılı Yapı Yaklaşık Birim Maliyetleri. Çevre ve Şehircilik Bakanlığı: Ankara; 2019. 